\title{
UJI PUPUK HAYATI TERHADAP PERTUMBUHAN DAN HASIL UBI JALAR (Ipomea batatas $L$ )
}

\author{
Daniel Kristanto*, Priyono ${ }^{* *}$, Saiful Bahri** \\ *Fakultas Pertanian, Universitas Slamet Riyadi, Surakarta, E-mail: daniellkriss@ gmail.com \\ **Fakultas Pertanian, Universitas Slamet Riyadi, Surakarta
}

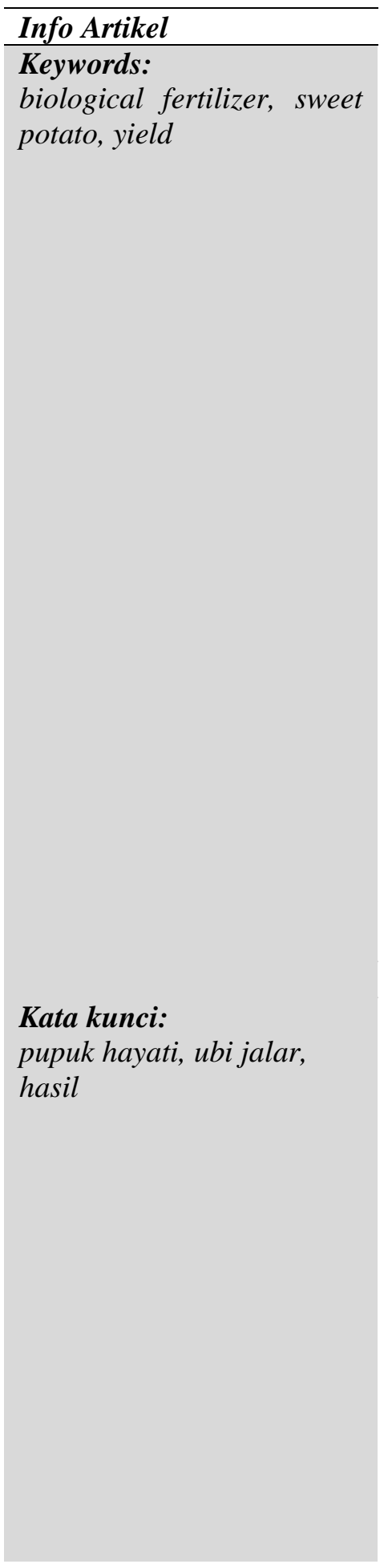

\begin{abstract}
The research on "Biological Fertilizer Test on Growth and Yield of Sweet Potatoes (Ipomea batatas L)" was carried out on 8 November 2018 to 8 March 2019 in rice fields with grumusol soil types, in Kalikijing Hamlet, Potronayan Village, Nogosari District, Boyolali Regency. The purpose of this study is (1) find out the suitable dosage Sinar Bio biofertilizer for sweet potato growth and yield (Ipomea batatas L), (2) find out the suitable Mycogrow biofertilizer for sweet potato growth and yield (Ipomea batatas L), (3) find out the suitable dosage of Natura biofertilizer for sweet potato growth and yield (Ipomea batatas L). This study used a single complete Randomized Completely Block Design $(R C B D)$ with three time replications with 9 treatment combinations: (P1: Sinar Bio Biofertilizer with $15 \mathrm{~kg} / \mathrm{ha}$ of biological fertilizer), (P2: Sinar Bio Biofertilizer with $30 \mathrm{~kg} / \mathrm{Ha}$ biological fertilizer), (P3: Sinar Bio Biofertilizer with $45 \mathrm{~kg} / \mathrm{Ha}$ biological fertilizer), (P4: Mycogrow Biofertilizer with $5 \mathrm{~kg} / \mathrm{ha}$ of biofertilizer), (P5: Mycogrow Biofertilizer with $10 \mathrm{~kg} / \mathrm{ha}$ of biofertilizer), (P6: Mycogrow Biofertilizer with $15 \mathrm{~kg} / \mathrm{ha}$ of biological fertilizer), ( P7: Natura Biofertilizer with $50 \mathrm{~kg} / \mathrm{ha}$ of biological fertilizer), (P8: Natura Biofertilizer with $75 \mathrm{~kg} / \mathrm{ha}$ of biological fertilizer), (P9: Natura Biofertilizer with $100 \mathrm{~kg} / \mathrm{ha}$ of biological fertilizer). The results showed that the treatment of biological fertilizer did not affect all observational parameters, stem length, number of branches, wet weight of stover, dry weight of stover, tuber weight, number of tubers, tuber diameter and harvest index.
\end{abstract}

\section{Abstrak}

Penelitian tentang "Uji Pupuk Hayati Terhadap Pertumbuhan Dan Hasil Ubi Jalar (Ipomea batatas L)" telah dilaksanakan pada tanggal 8 November 2018 sampai tanggal 8 Maret 2019 di lahan sawah dengan jenis tanah grumusol, di Dusun Kalikijing, Kelurahan Potronayan, Kecamatan Nogosari, Kabupaten Boyolali. Tujuan dilakukannya penelitian ini yaitu (1) mengetahui dosis pupuk hayati Sinar Bio yang tepat untuk pertumbuhan dan hasil Ubi jalar (Ipomea batatas L), (2) mengetahui dosis pupuk hayati Mikoriza yang tepat untuk pertumbuhan dan hasil Ubi jalar (Ipomea batatas L), (3) mengetahui dosis pupuk hayati Natura yang tepat untuk pertumbuhan dan hasil Ubi jalar (Ipomea batatas L). Penelitian ini menggunakan Rancangan Acak Kelompok Lengkap (RAKL) faktor tunggal dengan tiga kali ulangan dengan 9 kombinasi perlakuan: (P1 : Pupuk Hayati Sinar Bio dengan dosis pupuk hayati $15 \mathrm{~kg} / \mathrm{Ha}$ ), (P2 : Pupuk Hayati Sinar Bio dengan dosis pupuk hayati $30 \mathrm{~kg} / \mathrm{Ha}$ ), (P3 : Pupuk Hayati Sinar 
Bio dengan dosis pupuk hayati $45 \mathrm{~kg} / \mathrm{Ha}$ ), (P4 : Pupuk Hayati Mycogrow dengan dosis pupuk hayati $5 \mathrm{~kg} / \mathrm{Ha}$ ), (P5 : Pupuk Hayati Mycogrow dengan dosis pupuk hayati10 kg/Ha), (P6 : Pupuk Hayati Mycogrow dengan dosis pupuk hayati $15 \mathrm{~kg} / \mathrm{Ha}$ ), (P7 : Pupuk Hayati Natura dengan dosis pupuk hayati $50 \mathrm{~kg} / \mathrm{Ha}$ ), (P8 : Pupuk Hayati Natura dengan dosis pupuk hayati $75 \mathrm{~kg} / \mathrm{Ha}$ ), (P9 : Pupuk Hayati Natura dengan dosis pupuk hayati $100 \mathrm{~kg} / \mathrm{Ha}$ ). Hasil penelitian menunjukkan, perlakuan macam pupuk hayati tidak berpengaruh pada semua parameter pengamatan, yaitu panjang batang, jumlah cabang, berat basah brangkasan, berat kering brangkasan, berat umbi, jumlah umbi, diameter umbi dan indeks panen.

\section{PENDAHULUAN}

Pertanian Indonesia saat ini sebagian besar masih bergantung pada penggunaan pupuk anorganik dan pestisida. Penggunaan pupuk anorganik dan pestisida dengan tidak mengindahkan dosis dan konsentrasi dalam jangka panjang akan mempengaruhi kesuburan tanah, bahkan dapat merusak tanah. Kerusakan tanah akan mengakibatkan terjadinya beberapa hal, yaitu musnahnya organisme penyubur tanah karena pupuk anorganik, kesuburan tanah yang merosot, rusaknya keseimbangan ekosistem tanah dan terjadi peledakan dan serangan hama (Manuhuttu et al, 2018).

Pupuk merupakan zat yang ditambahkan ke dalam tanah yang bertujuan untuk meningkatkan pasokan unsur hara dalam tanah yang berguna untuk pertumbuhan tanaman. Dalam pemupukan ada beberapa hal yang harus di perhatikan, yaitu tanaman yang akan dipupuk, jenis tanah yang akan dipupuk, jenis pupuk yang digunakan, dosis pupuk yang diberikan, waktu pemupukan dan cara pemupukan (Hardjowigeno, 2015). Pertanian ramah lingkungan merupakan usaha pertanian yang bertujuan untuk memperoleh produksi maksimal tanpa merusak lingkungan, baik secara fisik, kimia, biologi, dan ekologi. Pupuk hayati berbeda dengan pupuk kimia buatan, misalnya Urea, TSP dan lainlain, karena dalam pupuk hayati komponen utamanya adalah jasad hidup yang diperoleh dari alam tanpa ada penambahan bahan kimia kecuali bahan kimia yang diperlukan untuk mendukung pertumbuhan jasad hidup selama masa penyimpanan (Yuwono, 2012).

Ubi jalar mengandung kalori, serat, vitamin, dan mineral yang cukup baik. Kandungan vitamin pada ubi jalar dalam bentuk $\beta$-carotene, thiamin, riboflavin, niacin, dan ascorbic acid setara dengan kandungan vitamin yang terdapat padawortel dan tomat. Ubi jalar juga mempunyai kandungan vitamin A dan C yang lebih tinggi di antara ubi-ubian lainnya (Zuraida, 2019). Di Papua dan Maluku, komoditas ini bahkan digunakan sebagai makanan pokok. Di antara kelompok umbi-umbian, ubi jalar merupakan salah satu pangan lokal yang berpotensi untuk dikembangkan. Hal ini didasarkan pada pertimbangan bahwa ubi jalar karena merupakan sumber karbohidrat, mempunyai potensi produktivitas yang tinggi, memiliki potensi diversifikasi produk yang cukup beragam, memiliki kandungan zat gizi yang beragam dan memiliki potensi permintaan memiliki permintaan pasar baik lokal, maupun ekspor yang terus meningkat (Adrianus,2012).

Tujuan dilakukannya penelitian ini adalah untuk menguji pengaruh macam pupuk hayati terhadap pertumbuhan dan hasil ubi jalar (Ipomea batatas L). Tujuan dari penelitian ini yaitu: mengetahui dosis pupuk hayati Sinar Bio yang tepat untuk pertumbuhan dan hasil Ubi jalar (Ipomea batatas $L$ ), mengetahui dosis pupuk hayati Mikoriza yang tepat untuk pertumbuhan dan hasil Ubi jalar (Ipomea batatas L) dan mengetahui dosis pupuk hayati Natura yang tepat untuk pertumbuhan dan hasil Ubi Jalar (Ipomea batatas L).

\section{BAHAN DAN METODE}

Penelitian ini menggunakan Rancangan Acak Kelompok Lengkap (RAKL) faktor tunggal yang terdiri dari 3 perlakuan dan 3 ulangan (blok), sehingga terdapat 9 satuan perlakuan (petak). 
Setiap petak perlakuan terdiri dari 9 tanaman sampel. P1 : Pupuk Hayati Sinar Bio dengan dosis 15 $\mathrm{kg} / \mathrm{Ha}, \mathrm{P} 2$ : Pupuk Hayati Sinar Bio dengan dosis $30 \mathrm{~kg} / \mathrm{Ha}, \mathrm{P} 3$ : Pupuk Hayati Sinar Bio dengan dosis $45 \mathrm{~kg} / \mathrm{Ha}, \mathrm{P} 4$ : Pupuk Hayati Mycogrow dengan dosis $5 \mathrm{~kg} / \mathrm{Ha}$, P5 : Pupuk Hayati Mycogrow dengan dosis $10 \mathrm{~kg} / \mathrm{Ha}$, P6 : Pupuk Hayati Mycogrow dengan dosis $15 \mathrm{~kg} / \mathrm{Ha}, \mathrm{P} 7$ : Pupuk Hayati Natura dengan dosis $50 \mathrm{~kg} / \mathrm{Ha}, \mathrm{P} 8$ : Pupuk Hayati Natura dengan dosis $75 \mathrm{~kg} / \mathrm{Ha}$, P9 : Pupuk Hayati Natura dengan dosis $100 \mathrm{~kg} / \mathrm{Ha}$. Penelitian ini telah dilaksanakan pada tanggal 8 November 2018 sampai tanggal 8 Maret 2019 di lahan sawah dengan jenis tanah grumusol, di Dusun Kalikijing, Kelurahan Potronayan, Kecamatan Nogosari, Kabupaten Boyolali. Bahan yang digunakan adalah bibit tanaman ubi jalar varietas Cilembu, pupuk anorganik, tanah, air, pupuk hayati Sinar Bio, pupuk hayati Mycogrow, pupuk hayati Natura. Alat yang digunakan adalah cangkul, sabit, cetok, pisau, penggaris, alat tulis, timbangan, papan penelitian, jangka sorong, oven, kertas koran.

\section{HASIL DAN PEMBAHASAN}

Hasil analisi ragam menunjukkan bahwa perlakuan pupuk hayati tidak berpengaruh nyata terhadap semua parameter pengamatan yaitu berupa panjang batang tanaman ubi jalar ketika tanaman berumur 120 hst, jumlah batang tanaman ubi jalar ketika tanaman berumur 120 hst, berat basah brangkasan tanaman, berat kering brangkasan tanaman, berat umbi, jumlah umbi, diameter umbi dan indeks panen.

Tabel 1. Pengamatan Pertumbuhan Tanaman

\begin{tabular}{ccccc}
\hline \multirow{2}{*}{ Perlakuan } & \multicolumn{4}{c}{ Purata } \\
\cline { 2 - 5 } & $\begin{array}{c}\text { Panjang Batang } \\
(\mathrm{cm})\end{array}$ & Jumlah Batang & $\begin{array}{c}\text { Berat Basah } \\
\text { Brangkasan }(\mathrm{g})\end{array}$ & $\begin{array}{c}\text { Berat Kering } \\
\text { Brangkasan }(\mathrm{g})\end{array}$ \\
\hline P1 & $203,1 \mathrm{a}$ & $4,00 \mathrm{a}$ & $1323 \mathrm{a}$ & $142,90 \mathrm{a}$ \\
P2 & $195,8 \mathrm{a}$ & $4,10 \mathrm{a}$ & $1297 \mathrm{a}$ & $161,29 \mathrm{a}$ \\
P3 & $203,8 \mathrm{a}$ & $4,10 \mathrm{a}$ & $1193 \mathrm{a}$ & $137,20 \mathrm{a}$ \\
P4 & $215,6 \mathrm{a}$ & $3,90 \mathrm{a}$ & $1133 \mathrm{a}$ & $130,64 \mathrm{a}$ \\
P5 & $191,2 \mathrm{a}$ & $4,10 \mathrm{a}$ & $1467 \mathrm{a}$ & $164,28 \mathrm{a}$ \\
P6 & $212,3 \mathrm{a}$ & $3,90 \mathrm{a}$ & $1253 \mathrm{a}$ & $144,86 \mathrm{a}$ \\
P7 & $206,2 \mathrm{a}$ & $4,20 \mathrm{a}$ & $1227 \mathrm{a}$ & $150,68 \mathrm{a}$ \\
P8 & $205,4 \mathrm{a}$ & $4,20 \mathrm{a}$ & $1260 \mathrm{a}$ & $147,31 \mathrm{a}$ \\
P9 & $199,2 \mathrm{a}$ & $4,80 \mathrm{a}$ & $1027 \mathrm{a}$ & $129,50 \mathrm{a}$ \\
\hline
\end{tabular}

Keterangan: angka yang di ikuti dengan huruf yang sama berarti berbeda tidak nyata.

\section{Pengaruh Pupuk Hayati Terhadap Pertumbuhan Tanaman Ubi Jalar}

Tabel 1 menunjukan bahwa perlakuan pemberian Pupuk Hayati tidak berpengaruh pada parameter pertumbuhan ubi jalar, yaitu panjang batang, jumlah cabang, berat basah brangkasan, berat kering brangkasan. Hal ini terjadi karena tanaman ubi jalar Cilembu ditanam pada suhu $27^{\circ} \mathrm{C}-29^{\circ} \mathrm{C}$ pada ketinggian $150 \mathrm{mdpl}$, diatas suhu syarat tumbuh ubi jalar Cilembu, juga tanaman ubi jalar Cilembu ditanam pada awal musim hujan sehingga curah hujan yang tinggi. Pernyataan ini senada dengan pernyataan Yowono $d k k$. (2006) pertumbuhan dan hasil maksimal tanaman tidak hanya ditentukan oleh hara yang cukup (sifat kimia) dan seimbang tetapi juga memerlukan lingkungan yang baik termasuk sifat fisik, dan biologis tanah. Menurut Sinulingga et al. (2015) keberhasilan penggunaan pupuk hayati tidak hanya dipengaruhi oleh kuantitas mikroba namun juga faktor lingkungan seperti suhu, curah hujan dan bahan organik. 
Pengaruh Pupuk Hayati Terhadap HasilTanaman Ubi Jalar

Tabel 2. Pengamatan hasil tanaman.

\begin{tabular}{ccccc}
\hline \multirow{2}{*}{ Perlakuan } & \multicolumn{4}{c}{ Purata } \\
\cline { 2 - 5 } & Berat Umbi (g) & Jumlah Umbi & $\begin{array}{c}\text { Diameter Umbi } \\
(\mathrm{cm})\end{array}$ & Indeks Panen \\
\hline P1 & $337 \mathrm{a}$ & $4,73 \mathrm{a}$ & $2,48 \mathrm{a}$ & $0,27 \mathrm{a}$ \\
P2 & $360 \mathrm{a}$ & $3,27 \mathrm{a}$ & $2,47 \mathrm{a}$ & $0,30 \mathrm{a}$ \\
P3 & $367 \mathrm{a}$ & $3,80 \mathrm{a}$ & $1,76 \mathrm{a}$ & $0,32 \mathrm{a}$ \\
P4 & $353 \mathrm{a}$ & $3,80 \mathrm{a}$ & $2,07 \mathrm{a}$ & $0,32 \mathrm{a}$ \\
P5 & $290 \mathrm{a}$ & $2,87 \mathrm{a}$ & $1,98 \mathrm{a}$ & $0,21 \mathrm{a}$ \\
P6 & $343 \mathrm{a}$ & $4,67 \mathrm{a}$ & $1,89 \mathrm{a}$ & $0,28 \mathrm{a}$ \\
P7 & $293 \mathrm{a}$ & $3,20 \mathrm{a}$ & $1,57 \mathrm{a}$ & $0,25 \mathrm{a}$ \\
P8 & $360 \mathrm{a}$ & $3,13 \mathrm{a}$ & $2,15 \mathrm{a}$ & $0,29 \mathrm{a}$ \\
P9 & $390 \mathrm{a}$ & $3,07 \mathrm{a}$ & $2,31 \mathrm{a}$ & $0,36 \mathrm{a}$ \\
\hline
\end{tabular}

Keterangan: angka yang di ikuti dengan huruf yang sama berarti berbeda tidak nyata.

Tabel 2 menunjukan bahwa perlakuan pemberian Pupuk Hayati tidak berpengaruh pada parameter hasil ubi jalar, yaitu berat umbi, jumlah umbi, diameter umbi dan indeks panen. Hal ini karena tanaman ubi jalar Cilembu ditanam pada suhu $27^{\circ} \mathrm{C}-29^{\circ} \mathrm{C}$ pada ketinggian $150 \mathrm{mdpl}$, diatas suhu syarat tumbuh ubi jalar Cilembu, juga tanaman ubi jalar Cilembu ditanam pada awal musim hujan sehingga curah hujan yang tinggi. Pernyataan ini senada dengan pernyataan Yuwono $d k k$. (2006) pertumbuhan dan hasil maksimal tanaman tidak hanya ditentukan oleh hara yang cukup (sifat kimia) dan seimbang tetapi juga memerlukan lingkungan yang baik termasuk sifat fisik, dan biologis tanah. Menurut Juanda dan Cahyono (2000), faktor lingkungan seperti temperatur, kelembaban udara, curah hujan, penyinaran matahari, letak geografi tanah, tofografi, dan sifat tanah, sangat mempengaruhi pertumbuhan ubi jalar. Umbi pada tanaman ubi jalar tidak dapat tumbuh sempurna karena tanaman tumbuh pada tanah grumusol / vertisol, yaitu tanah dengan kadar liat lebih dari $30 \%$,

bersifat mengembang dan mengerut. Tanah grumusol memiliki sifat fisik yang kurang baik untuk tanaman umbi-umbian. Hal ini didukung oleh penelitian Prasetyo, B. H. (2007) tingginya kandungan fraksi liat berkombinasi dengan dominasi mineral smektit merupakan salah satu penyebab sifat vertisol yang sulit diolah bila basah dan sangat keras bila kering. Pada tanah vertisol umumnya sifat fisik tanah lebih merupakan kendala dibanding sifat kimia tanah. Kendala utama untuk tanaman adalah tektur yang liat berat, sifat mengembang dan mengkerut, kecepatan infiltrasi air yang rendah, serta drainase yang lambat (Mukanda and Mapiki, 2001).

\section{KESIMPULAN}

Berdasarkan hasil penelitian maka dapat disimpulkan bahwa uji macam pupuk hayati tanaman ubi jalar tidak berpengaruh nyata terhadap semua parameter pertumbuhan dan hasil tanaman ubi jalar yaitu panjang sulur, jumlah cabang, berat brangkasan basah, berat brangkasan kering, berat umbi, jumlah umbi, diameter umbi dan indeks panen. Hal ini karena tanaman ubi jalar Cilembu ditanam pada suhu $27^{\circ} \mathrm{C}-29^{\circ} \mathrm{C}$ pada ketinggian $150 \mathrm{mdpl}$, diatas suhu syarat tumbuh ubi jalar Cilembu, juga tanaman ubi jalar Cilembu ditanam pada awal musim hujan sehingga curah hujan yang tinggi., keberhasilan penggunaan pupuk hayati tidak hanya dipengaruhi oleh kuantitas mikroba namun salah satunya faktor lingkungan seperti suhu, curah hujan, bahan organik dan juga karena tanaman penelitian tumbuh pada tanah grumusol / vertisol, yaitu tanah dengan kadar liat lebih dari 30\%, bersifat mengembang dan mengerut, drainase tanah yang sangat lambat, kecepatan infiltrasi rendah, sehingga kurang baik untuk tanaman umbi- umbian.Varietas Anjasmoro dengan jarak tanam $30 \mathrm{~cm} \mathrm{x}$ $40 \mathrm{~cm}$ menghasilkan tingkat serangan hamanya tinggi dan dapat memberikan hasil yang kurang optimal dibandingkan dengan varietas Grobogan. 


\section{DAFTAR PUSTAKA}

Adrianus. 2012. Pertumbuhan dan Hasil Tiga Varietas Ubi Jalar (Ipomoea batatas L.) Pada Tinggi Petakan yang Berbeda. Jurnal Agricola. Hlm. 49-69

Badan Pusat Statistik. 2015. Produksi Ubi Jalar Menurut Provinsi (ton). Badan Pusat Statistik, Jakarta.

Badan Pusat Statistik. 2015. Luas Panen Ubi Jalar Menurut Provinsi (ton). Badan Pusat Statisstik, Jakarta.

Cahyono, B. 2003. Teknik dan Strategi Budidaya Sawi Hijau (Pat- Tsai). Penerbit Yayasan Pustaka Nusantara, Yogyakarta.

Cahyono, Ir Bambang. 2000. Ubi Jalar, Budi Daya dan Analisis Usaha Tani. Kanisius, Yogyakarta.

Direktorat Budidaya Serealia. 2013. Kebijakan Direktorat Jenderal Tanaman Pangan dalam Pengembangan Komoditas Jagung, Sorgum dan Gandum. Direktorat Jenderal Tanaman Pangan. Kementrian Pertanian, Jakarta.

Djaenudin, D., H. Marwan, H. Subagyo dan Hidayat, A. 2003. Petunjuk Teknis Evaluasi Lahan untuk Komoditas Pertanian. Balai Penelitian Tanah, Puslitbangtanak. Badan Penelitian dan Pengembangan Pertanian. Bogor

Fadiluddin, M. 2009. Efektivitas Formula Pupuk Hayati Dalam Memacu Serapan Hara, Produksi Dan Kualitas Hasil Jagung Dan Padi Gogo Di Lapang. Tesis, Bogor: Institut Pertanian Bogor.

Fagi, A.M. 2015. Landasan Strategis Pembangunan Pertanian Dan Peningkatan Produksi Pangan Berkelanjutan Dalam Sumbangan Pemikiran Strategi Pencapaian Dan Pemantapan Kemandirian Pangan. Dilihat Dari Aspek Sumber Daya, Kemiskinan, Penelitian, Dan Penyuluhan: Refleksi 2001-2005. IAARD PRESS. 2015: 5-40.

Hardjowigeno, Sarwono. 2015. Ilmu Tanah. Akademika Pressindo, Jakarta. Juanda, D dan B.

Cahyono. 2000. Ubi Jalar: Budi Daya Dan Usaha Taninya. Kanisius, Yogyakarta.

Kementrian Pertanian. 2016. Outlook: Komoditas Pertanian Sub Sektor Tanaman Pangan. Pusat Data dan Sistem Informasi Pertanian Kementrian Pertanian, Jakarta.

Mukanda, N. and A. Mapiki. 2001. Vertisols Management in Zambia. p.129-27. In Syers, J. K, F. W. T. Penning De Vries, and P. Nyamudeza (Eds): The Sustainable Management of Vertisols. IBSRAM Proceedings No. 20.

Manuhuttu, A. P., Rehatta, H., \& Kailola, J. J. G. 2018. Pengaruh Konsentrasi Pupuk Hayati Bioboost Terhadap Peningkatan Produksi Tanaman Selada (Lactuca sativa. L). Agrologia, $3(1)$.

Onggo, T.M. 2006. Perubahan Komposisi Pati Dan Gula Dua Jenis Ubi Jalar Nirkum “Cilembu” Selama Peyimpanan. Jurnal Bionatura 8 (2):161-170.

Patola, Lidia Natalidini Putri. 2017. Pengaruh Penggunaan Pupuk Hayati Dan Perbedaan Jenis Tanah Terhadap Pertumbuhan Dan Hasil Garut. Innofarm 17.1

Puslitbangtan. 2002. Deskripsi Varietas Unggul Padi dan Palawija 2001-2002. Pusat Penelitian dan Pengembangan Tanaman Pangan, Bogor.

Prasetyo, B. H. 2007. Perbedaan Sifat-Sifat Tanah Vertisol Dari Berbagai Bahan Induk. Jurnal Ilmu-Ilmu Pertanian Indonesia, 9(1), 20-31.

Putri, I. K., Kusuma, Z., \& Prijono, S. 2018. Aplikasi Pupuk Hayati Majemuk Cair Pada Tanaman Tebu Di PT. Perkebunan Nusantara X Kediri. Jurnal Tanah dan Sumberdaya Lahan, 5(1), 681-688.

Rukmana, R. 2014. Ubi Jalar Budidaya dan Pascapanen. Kanisius, Jogyakarta Inc.

Saleh, N., Rahayuningsih, S. A., \& Widodo, Y. 2018. Profil Dan Peluang Pengembangan Ubi Jalar Untuk Mendukung Ketahanan Pangan Dan Agroindustri. Hlm 21-30

Sarwono, B. 2005. Ubi Jalar: Cara Budidaya Yang Tepat, Efisien, Dan Ekonomis. Penebar Swadaya, Jakarta 
Setiawati, M. R., Sofyan, E. T., Nurbaity, A., Suryatmana, P., \& Marihot, G.P. 2018. Pengaruh Aplikasi Pupuk Hayati, Vermikompos Dan Pupuk Anorganik Terhadap Kandungan N, Populasi Azotobacter sp. Dan Hasil Kedelai Edamame (Glycine max (L.) Merill) Pada Inceptisols Jatinangor. Agrologia, 6(1).

Sinulingga. E. S., J. Ginting dan T. Sabrina. 2015. Pengaruh Pemberian Pupuk Hayati Cair Danpupuk NPK Terhadap Pertumbuhan Bibit Kelapa Sawit Di Pre Nursery. Jurnal Agroekoteknologi. 3 (3): 1219-1225.

Sonhaji, A. 2000. Mengenal dan Bertanam Ubi Jalar. Gaza Publishing, Bandung.

Sumarno, dan U.G. K artasasmita. 2012. Kesiapan Petani Menggunakan Pupuk Organik pada Padi Sawah. Jurnal Penelitian Pertanian Tanaman Pangan 31(3): 137-144.

Sutrisna, Nana, Yati Haryati, Ebet Nurbaeti. 2015. Petunjuk Teknis Budidaya Ubi Cilembu. Balai Pengkajian Teknologi Pertanian, Bandung.

Syam, M. 2008. Padi Organik dan Tuntutan Peningkatan Produksi Beras. Jurnal Iptek Tanaman Pangan 3(1): 1-8. Wargiono, J., A. Hasanuddin, dan Suyamto. 2006. Teknologi Produksi Ubikayu Mendukung Industri Bioethanol. Puslitbangtan Bogor; $42 \mathrm{hlm}$.

Yuwono, Triwibowo. 2012. Bioteknologi Pertanian. Gadjah Mada University Press, Yogyakarta.

Yopie, M., M.U. Harun, Munandar, R., Hayati, dan N. Gafa. 2012. Pemanfaatan Berbagai Jenis Pupuk Hayati Pada Budidaya Tanaman Jagung (Zea Mays. L) Efisien Hara Di Lahan Kering Marginal. Jurnal lahan suboptimal (1)1: 31-39.

Zuraida, Nani. 2019. Status Ubi Jalar Sebagai Bahan Diversifikasi Pangan Sumber Karbohidrat. Iptek Tanaman Pangan Vol. 4 No. 1 - 2009 